\title{
Musical Training Enhances Automatic Encoding of Melodic Contour and Interval Structure
}

\author{
Takako Fujioka ${ }^{1,4}$, Laurel J. Trainor ${ }^{3}$, Bernhard Ross ${ }^{1,2}$, \\ Ryusuke Kakigi ${ }^{4}$, and Christo Pantev ${ }^{1,2}$
}

\begin{abstract}
In music, melodic information is thought to be encoded in two forms, a contour code (up/down pattern of pitch changes) and an interval code (pitch distances between successive notes). A recent study recording the mismatch negativity (MMN) evoked by pitch contour and interval deviations in simple melodies demonstrated that people with no formal music education process both contour and interval information in the auditory cortex automatically. However, it is still unclear whether musical experience enhances both strategies of melodic encoding. We designed stimuli to examine contour and interval information separately. In the contour condition there were eight different standard melodies (presented on $80 \%$ of trials), each consisting of five notes all ascending in pitch, and the corresponding deviant melodies (20\%) were altered to descending on their final note. The interval condition used one five-note standard melody transposed to eight
\end{abstract}

\section{INTRODUCTION}

Musical ability is an essential component of human nature and there is no known human society past or present without music (Wallin, Merker, \& Brown, 2000). Across different societies, musical structure has two aspects, involving time (rhythm) and pitch (Deutsch, 1999), although the particular instantiations differ from one musical system to another. From a perceptual point of view, sequences of tones, or melodies, have two aspects, a contour and an interval code (Dowling, 1978, 1982). The contour representation consists of information about the up and down pattern of pitch changes, regardless of their exact size, and is common to both speech prosody and musical melody (Patel, Peretz, Tramo, \& Labreque, 1998). The interval representation consists of the exact ratio of pitch between successive tones and is specific to music, forming the basis from which scales and harmony can emerge. Behavioral studies have provided evidence that contour is more funda-

\footnotetext{
${ }^{1}$ The Rotman Research Institute, Baycrest Centre for Geriatric Care, ${ }^{2}$ University of Münster, ${ }^{3}$ McMaster University, ${ }^{4}$ National Institute for Physiological Sciences
}

keys from trial to trial, and on deviant trials the last note was raised by one whole tone without changing the pitch contour. There was also a control condition, in which a standard tone $(990.7 \mathrm{~Hz})$ and a deviant tone $(1111.0 \mathrm{~Hz})$ were presented. The magnetic counterpart of the MMN (MMNm) from musicians and nonmusicians was obtained as the difference between the dipole moment in response to the standard and deviant trials recorded by magnetoencephalography. Significantly larger MMNm was present in musicians in both contour and interval conditions than in nonmusicians, whereas $\mathrm{MMNm}$ in the control condition was similar for both groups. The interval MMNm was larger than the contour MMNm in musicians. No hemispheric difference was found in either group. The results suggest that musical training enhances the ability to automatically register abstract changes in the relative pitch structure of melodies.

mental than interval in that both infants and musically untrained adults are able to process contour information but have difficulties encoding the intervals of unfamiliar melodies (Trehub, Trainor, \& Unyk, 1993; Bartlett \& Dowling, 1980; Dowling, 1978; Cuddy \& Cohen, 1976). The pitch intervals of unfamiliar melodies are better perceived by trained than untrained musicians (Trainor, Desjardins, \& Rockel, 1999; Peretz \& Babaï, 1992).

How is melodic information processed, stored, and retrieved in the brain, and what is the effect of musical training? Several behavioral studies support the idea that plastic changes in the brain caused by years of training enable superior musical perception and performance. For example, it has been reported that musicians show a left hemispheric dominance in recognizing melodic sequences while nonmusicians show a right hemispheric dominance (Bever \& Chiarello, 1974). As well, musicians demonstrate better performance in the left hemisphere than the right hemisphere when they are asked to recognize a part of a melodic sequence (Peretz \& Babaï, 1992).

Recent neuroimaging investigations have begun to identify brain structures relevant for music processing (e.g., Tillmann, Janata, \& Bharucha, 2003; Janata et al., 
2002; Koelsch et al., 2002; Ohnishi et al., 2001; Satoh, Takeda, Nagata, Hatazawa, \& Kuzuhara, 2001; Halpern \& Zatorre, 1999; Platel et al., 1997; Zatorre, Evans, \& Meyer, 1994). For example, a functional magnetic resonance imaging (fMRI) study has shown that listening to music produces an enhanced activation in the planum temporale and the left posterior dorsolateral prefrontal cortex in musicians, in comparison to pure tones (Ohnishi et al., 2001). Long-term musical training has both anatomical and functional consequences. For example, anatomical asymmetries in the auditory cortices of musicians were reported using high-resolution MRI. The left planum temporale was larger than the right in skilled musicians, especially in those with absolute pitch (the ability to recognize and name the pitch of a musical tone without reference to a comparison tone) (Schlaug, Jäncke, Huang, \& Steinmetz, 1995). Furthermore, the specific anterior subregion of the corpus callosum was found to be larger in musicians who commenced musical training before the age of seven (Schlaug, Jäncke, Huang, Staiger, \& Steinmetz, 1995). Functional differences in musicians have also been demonstrated, mainly in the sensorimotor and in the auditory systems. Violinists practice rapid independent movement of the fingers of their left hand on the fingerboard of their instrument every day for many years. Somatosensory-evoked magnetic fields reveal the results of this experience in larger cortical representations of the left-hand fingers of musicians in comparison to either the right-hand fingers of musicians or the fingers of control subjects who never played a violin (Elbert, Pantev, Wienbruch, Rockstroh, \& Taub, 1995). In contrast, behavioral and functional MRI studies on pianists (Jäncke, Shah, \& Peters, 2000; Jäncke, Schlaug, \& Steinmetz, 1997) have found less asymmetrical activity in the motor cortices of musicians than in those of control subjects, since keyboard performance requires similar motor control skills for both hands. Furthermore, transcranial magnetic stimulation (TMS) data demonstrated that bimanual motor activities in keyboard musicians were less inhibited than in normal subjects (Ridding, Brouwer, \& Nordstrom, 2000), as is predicted from the observation of an enlarged corpus callosum in musicians (Schlaug, Jäncke, Huang, Staiger, et al., 1995). Musicians and nonmusicians also differ in their evoked responses from auditory cortex. A magnetoencephalography (MEG) study reveals that musicians show larger amplitude auditory evoked N1m responses (peaking at about $100 \mathrm{msec}$ after stimulus onset) for piano sounds (Pantev et al., 1998) and an electroencephalography (EEG) study reveals that they show larger P2 and N1c responses (Shahin, Bosnyak, Trainor, \& Roberts, 2003). Furthermore, the effect of N1m enhancement is specific to the instrument of training (Pantev, Roberts, Schulz, Engelien, \& Ross, 2001). Event related potential (ERP) studies have also demonstrated differences between musicians and nonmusicians in later processing that is likely outside primary or second- ary sensory areas. Besson, Faïta, \& Requin (1994) and Trainor et al. (1999) report enhanced late positive waves between 300 and 600 msec. Relations between functional and anatomical measures are also emerging. Schneider et al. (2002) combined structural information from MRI and functional information from MEG to reveal a correlation between Heschl's gyrus enlargement and enhanced evoked magnetic field response in the latency of 19-30 msec in musicians. In summary, the comparison of brain responses between skilled musicians and naive subjects can give us new insights into brain plasticity associated with musical training.

The ability to encode an acoustical context is reflected electrophysiologically in the mismatch negativity (MMN) component of ERPs. The MMN and its magnetic counterpart, the MMNm, are elicited within about 100 to 200 msec after any discriminable change that occurs infrequently in a repeatedly presented auditory stimuli, even when the stimulus is not attended (Picton et al., 2000; Näätänen \& Picton, 1987; Näätänen, 1992). The MMN reflects processing in neural memory traces by which the auditory cortex handles representations of the recent acoustic past and its repetitive aspects. The sources of the MMN have been located mainly in the supratemporal plane (Alho, 1995) by dipole modeling (Scherg, Vajsar, \& Picton, 1989) and scalp current density (SCD) maps obtained from EEG (Giard, Perrin, Pernier, \& Bouchet, 1990) and MEG (Levänen, Ahonen, Hari, McEvoy, \& Sams, 1996). The contribution of frontal generators of MMN has been also suggested not only by SCD (Giard et al., 1990) but also by lesion studies (Alain, Woods, \& Knight, 1998; Alho, Woods, Algazi, Knight, \& Näätänen, 1994). MMN is elicited not only for changes in single acoustic features, but also for more complex and abstract features. Recent studies show that MMN can be obtained even by changes in an auditory pattern (Alain, Cortese, \& Picton, 1999; Alain, Woods, \& Ogawa, 1994) and a change from ascending to descending tone pairs (Saarinen, Paavilainen, Schröger, Tervaniemi, \& Näätänen, 1992). Furthermore, MMN is affected by experience such as phoneme categorization in a particular language (Phillips et al., 2000; Cheour et al., 1998; Näätänen et al., 1997). Even after a short time of intense listening training, the increase in MMN amplitude parallels the increased discrimination performance with tone frequency discrimination (Menning, Roberts, \& Pantev, 2000) or with foreign phoneme categories (Menning, Imaizumi, Zwitserlood, \& Pantev, 2002). These studies indicate that the conscious process of discrimination and the unconscious process of extracting changes in memory traces interact and that these two processes are affected by training.

The goal of the present study is to investigate the relationship between long-term musical training and automatic melodic processing. Changes in both pitch contour (Trainor, McDonald, \& Alain, 2002; Tervaniemi, Rytkonen, Schröger, Ilmoniemi, \& Näätänen, 2001; Paa- 
vilainen, Jaramillo, \& Näätänen, 1998; Tervaniemi, Maury, \& Näätänen, 1994; Saarinen et al., 1992) and pitch interval (Trainor et al., 2002) can evoke MMN responses from nonmusicians even when the pitch level are changed from trial to trial. However, no study to date has assessed musical training effects separately in contour and interval encoding. We investigated the MMNm responses to contour and interval changes in both musicians and nonmusicians. The stimuli were designed to clearly separate contour and the interval encoding. Factors in the musical context other than contour and interval, such as out-of-key changes, familiarity of melody, and the range of pitch leaps, were carefully controlled. A control condition examining frequency deviations to single tones was also included.

\section{RESULTS}

Clear auditory evoked magnetic fields (AEFs) were obtained from both musicians and nonmusicians in all stimulus conditions. The grand-averaged dipole moment waveforms for both groups are shown in Figure 1. P1m$\mathrm{N} 1 \mathrm{~m}-\mathrm{P} 2 \mathrm{~m}$ responses from the first to the fourth note were observed in both melodic conditions and in both groups. Those waveforms showed similar slow baseline shifts over the duration of the stimulus in both groups. Despite the smaller signal- to-noise ratio in the deviants (smaller number of trials) than standards, highly reproducible response patterns were obtained in both melodic conditions. After the onset of the fifth note, musicians showed clear MMNm responses in both hemispheres for both contour and interval conditions. In contrast, nonmusicians showed unclear responses in both contour and interval conditions. In the single tone control condition, on the other hand, both groups showed clear MMNm responses to the frequency change of the stimulus.

The magnified MMNm waveforms after onset of the deviation are shown in Figure 2 with the mean of 95\% confidence limits calculated using bootstrap resampling from every data point (shown as horizontal lines around zero from 50 to $250 \mathrm{msec}$ after onset of deviation). This allows us to identify the MMNm response significantly different from zero as the parts lying outside the limits. According to the analysis, musicians showed highly significant MMNm responses for the deviation of melodies at 100 to $200 \mathrm{msec}$ after onset. In contrast, the MMNm responses in nonmusicians reached significance only in the right hemisphere for the interval condition. For both groups, the MMN evoked by single tone frequency deviation was highly significant between 95 and 200 msec after stimulus onset.

The magnitude of MMNm for the two melodic conditions in the musician group was compared using the same analysis method. As shown in Figure 3, musicians showed significantly larger MMNm in the interval than in the contour condition. The data in nonmusicians was not compared, since the contour MMNm was not present significantly above baseline levels.

The MMNm peaks were slightly later in the interval condition compared to the contour condition, as displayed in Figure 2. However, individual response varied widely in morphology (i.e., single or double peak). This prevented an unambiguous identification of the MMNm peak latency in single subjects, which is required for statistics on the latency differences between the stimulus conditions.

The amplitudes of MMNm calculated around the peak latency of the grand-averaged waveforms are shown in Table 1 . The MMNm was significantly larger in musicians than nonmusicians according to the analysis of variance (ANOVA), $F(1,22)=12.787, p<.01$. MMNm was also significantly different across conditions (contour, interval, control), $F(2,44)=16.552, p<.0001$, and there was a significant interaction between group and condition, $F(2,44)=4.02, p<.05$. In musicians, the MMNm was significantly larger in the control and the interval than in the contour condition $(p<.05)$. The larger amplitude in the interval condition compared to the contour condition can also be seen in Figure 3. In nonmusicians, the MMNm amplitude was larger in control than both contour $(p<.0001)$ and interval conditions $(p<.01)$ as also clearly seen in the waveforms depicted in Figure 2. The factor hemisphere was not significant in any conditions for either group, nor did hemisphere interact with any other factors.

The results of the behavioral tests are reported in Table 2 . The performance of musicians was significantly better than that of nonmusicians according to the ANOVA, $F(1,22)=23.865, p<.0001$. Musicians exhibited good performance in both contour (96.50\%) and interval (95.83\%) conditions and they did not show significant differences between tasks. Nonmusicians performed at $63.0 \%$ in the interval task, which was above the chance levels of $50 \%, t(11)=3.564, p<.01$. However, their performance of $86.17 \%$ in the contour task was significantly better, $t(11)=5.946, p<.0001$, than in the interval task.

\section{DISCUSSION}

In the present study, musicians showed significantly larger MMNm responses than nonmusicians to deviations in melodic contour and interval structure, whereas both groups showed similar MMNm responses to frequency deviation in a single pure tone. As well, both groups tended to show larger MMNm responses to interval than to contour changes. The results strongly support the hypothesis that musical experience leads to specific changes in the neural mechanisms for processing of abstract, but not sensory, melodic information. The contour and interval processing must be performed at the level of melodic patterns because the overall pitch levels shifts from trial to trial. Because MMNm for simple 
Figure 1. Grand averages of the source space waveforms from both musicians and nonmusicians for each condition (contour, interval, and frequency-single tone) in both left and right hemispheres. The $y$-axis shows the dipole moment (positive upward), and the $x$-axis shows the time related to the stimulus onset. The standard averaged data, the deviant averaged data, and the difference between the deviant and the standard (MMNm response) are shown. The deviation of stimuli of both contour and interval conditions occur at the fifth note. Closed arrows indicated the clearly identifiable MMNm responses, whereas open arrows indicated the vague responses.

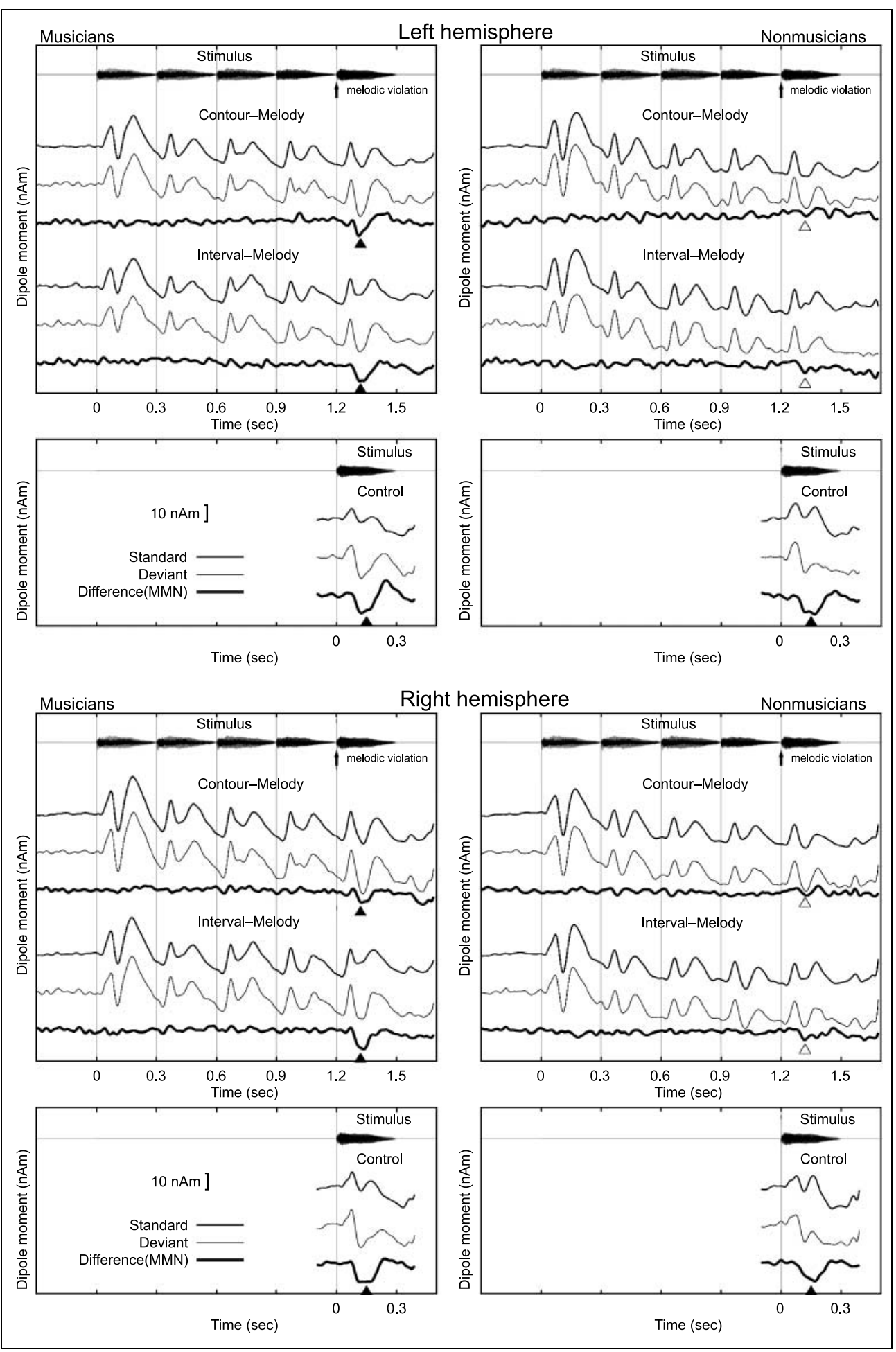

frequency deviation did not differ between the two groups, whereas MMNm to contour and interval changes did, we can conclude that musical training mainly affects the pitch contour and interval relations between tones rather than the encoding of single tones. These results extend a number of recent studies showing that MMN reflects not only the encoding of simple sensory features, but also the encoding of abstract rules and patterns in an auditory context (Trainor et al., 2002; Alain, Achim, \& Woods, 1999; Alain, Cortese, et al., 1999; Paavilainen et al., 1998; Alain et al., 1994; Saarinen et al., 1992), by showing differential effects of training on MMNm responses to different types of MMN. The results are also in line with observations of more pronounced MMN responses in musicians to the deviation of musicrelated stimuli, such as harmonic chord progressions 
Figure 2. The source space waveforms of MMNm. For both contour and interval condition the time scale on the $x$-axis refers to the onset of the fifth note. The thick line represents the MMNm response and thin lines above and below the zero line show the upper and lower limit of $95 \%$ confidence interval. The mean of confidence interval in the whole time series was subtracted from the response to adjust the baseline of MMNm waveform to the zero line.

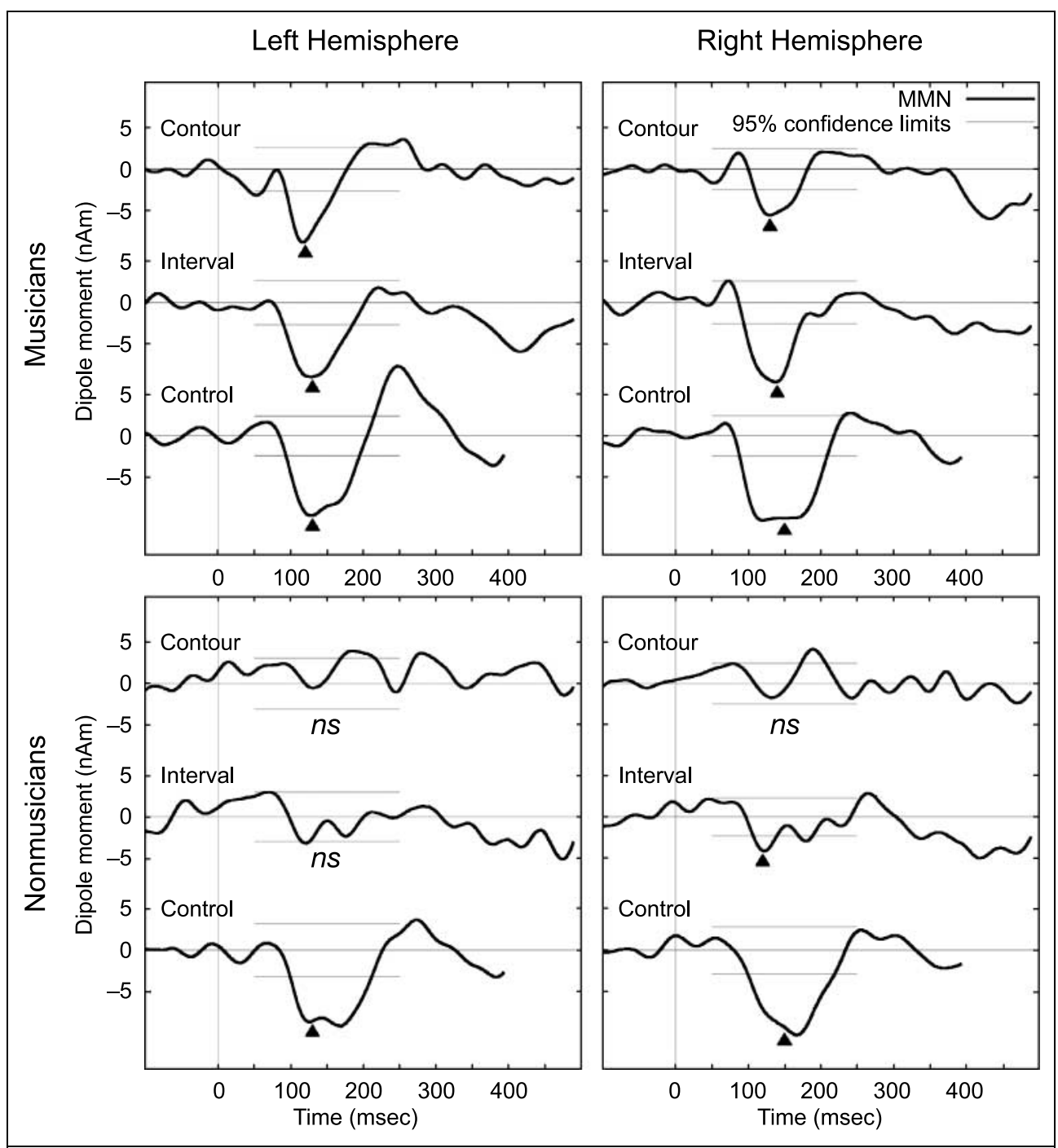

(Koelsch, Schröger, \& Tervaniemi, 1999), pitch sequences within a tonal structure (Brattico, Näätänen, \& Tervaniemi, 2002), and complex temporal patterns of tones (Tervaniemi, Ilvonen, Karma, Alho, \& Näätänen, 1997). The results also extend those of Tervaniemi et al. (2001) by showing that the enhancement in musicians is not restricted to contour processing, but also applies to interval processing without contour change.

On the other hand, the almost absent MMNm in nonmusicians in the present study is different from the previous observations of Trainor et al. (2002) of clear MMN to both contour and interval changes. There are likely two factors contributing to this difference. First the behavioral performance of nonmusicians in our study was much lower than that of nonmusicians in Trainor et al.'s study, as we modified their contour and interval stimuli. Specifically, we matched the size of pitch deviation across conditions, with the result that the contour melodies in our study had a smaller pitch range and therefore a smaller size of deviation for contour changes. The present interval melody is also more complicated than that of Trainor et al. in two important musical features. First, their standard melody, consisting of the first five notes of an ascending diatonic scale, was highly familiar and had a simple pitch contour, whereas

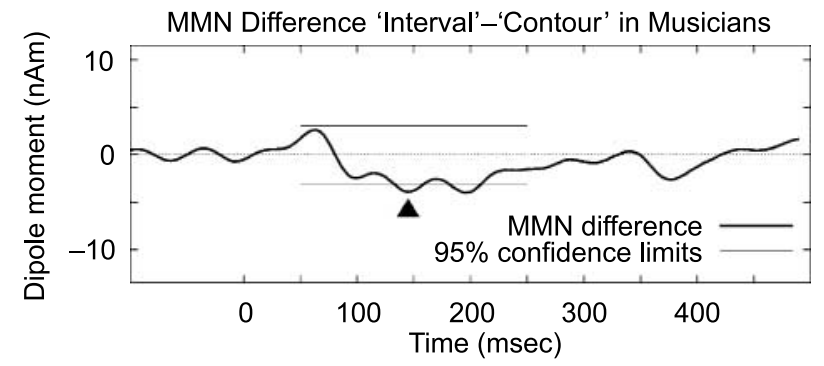

Figure 3. Comparison between interval and contour condition in musician's MMNm response. The difference waveform was obtained by subtraction of response for contour condition from interval condition combined across both hemispheres. 
Table 1. Mean of Dipole Moment ( \pm SEM) as the MMNm Amplitude of Each Hemisphere in Control, Contour and Interval Conditions

\begin{tabular}{|c|c|c|c|c|}
\hline \multirow[b]{2}{*}{ Subject Group } & \multirow[b]{2}{*}{$n$} & \multicolumn{3}{|c|}{ Dipole Moment (nAm) } \\
\hline & & Control & Contour & Interval \\
\hline \multicolumn{5}{|l|}{ Left hemisphere } \\
\hline Musicians & 12 & $9.737 \pm 1.543^{*}$ & $7.572 \pm 1.202$ & $9.644 \pm 1.197^{*}$ \\
\hline Nonmusicians & 12 & $9.742 \pm 2.418^{* * *, * *}$ & $-0.395 \pm 1.458$ & $3.061 \pm 1.086$ \\
\hline \multicolumn{5}{|l|}{ Right hemisphere } \\
\hline Musicians & 12 & $10.709 \pm 1.808^{*}$ & $5.773 \pm 1.078$ & $10.344 \pm 2.147^{*}$ \\
\hline Nonmusicians & 12 & $8.123 \pm 1.947^{* * *, * *}$ & $0.792 \pm 1.262$ & $3.732 \pm 1.052$ \\
\hline
\end{tabular}

the melody of the present study was unfamiliar and contained a more complex melodic contour. As well, the interval changes in Trainor et al.'s study contained outof-key notes, whereas ours did not. Naïve subjects more easily detect changes in a familiar melody than in an unfamiliar one, especially for nondiatonic changes (Besson \& Faïta, 1995; Besson et al., 1994). Thus, the task difficulty was certainly a contributing factor to the small amplitude MMN seen in the present study. A second major difference between studies was that we used MEG and analyzed data as represented in a negative oriented dipole source, whereas Trainor et al. used EEG. MEG is less sensitive than EEG in detecting radial oriented source current signals, which in the present case could be generated from multiple sources of MMN including frontal activation (Opitz, Rinne, Mecklinger, Von Cramon, \& Schröger, 2002; Rinne, Alho, Ilmoniemi, Virtanen, \& Näätänen, 2000; Alho, 1995; Giard et al., 1990).

Interestingly, MMNm responses were larger in the interval condition compared to the contour condition, despite the fact that we controlled for interval size and range across the conditions. Thus, we have no evidence that contour is a more fundamental process, or that it is neurally privileged, even the musically untrained. There are two possible explanations for the larger MMN to interval changes. The first concerns the relation between contour and interval information. Note that the melodic interval between successive notes essentially includes the up-and-down contour information as well. In other words, contour processing could be a part of the interval processing, even though it is hard to tell whether one of the processes comes first or both run in parallel. In the interval task, the same melody is presented transposed to different pitch levels on each trial. However, in the contour task, different intervals are present on each trial. If the auditory cortex automatically extracts interval information, and this information is irrelevant in the contour task, the presence of the constantly varying intervals could obscure the automatic response to the change in contour. In this case, the regularities of the standard melodies in the interval task could be extracted more easily than those of the contour melodies for which the various interval sizes need to be ignored. If correct, this suggests that contour information is extracted after or concurrently with interval information, but not before it. A second explanation concerns the fact that the changes in the present interval stimuli are accompanied by a change in tonality. That is, the terminal note of interval standard melody is the fifth note of the scale and functions strongly as the dominant in the key. Thus, it is possible that the MMNm was larger for interval than contour changes because not only was the interval processed, but also a difference in tonality was detected.

An explanation of the larger MMNm for interval than for contour changes must also account for the mismatch between the MMNm elicited and behavioral performance. The behavioral performance of musicians was almost perfect in both conditions. On the other hand, behavioral performance in nonmusicians was much better for contour than for interval changes, although MMNm was only significantly present for interval changes, and then only in the right hemisphere. Generally, MMN amplitude corresponds to behavioral accuracy (Winkler et al., 1999; Kraus, McGee, Carrell, \& Sharma,

Table 2. Mean \% Correct Performance $( \pm S E M)$ in the Behavioral Discrimination Task of Contour and Interval Conditions

\begin{tabular}{lccc}
\hline Subject Group & $n$ & Contour & Interval \\
\hline Musicians & 12 & $96.50 \pm 2.55$ & $95.83 \pm 1.90$ \\
Nonmusicians & 12 & $86.17 \pm 5.04^{*}$ & $63.00 \pm 3.65$ \\
\hline
\end{tabular}

$* p<.0001$. 
1995; Tiitinen, May, Reinikainen, \& Näätänen, 1994; Näätänen, Jiang, Lavikainen, Reinikainen, \& Paavilainen, 1993). However, some recent studies demonstrated that MMN responses emerge even before subjects consciously achieve the discrimination tasks in sound categorization (Allen, Kraus, \& Bradlow, 2000; Dalebout \& Stack, 1999; Tremblay, Kraus, \& McGee, 1998). The nonmusicians may have difficulty in performing the interval discrimination task behaviorally if it depends on higher cognitive and attentive processes such as categorization, memorization, and decision making, which utilize the output of the automatic MMN processes (Näätänen \& Alho, 1997; Näätänen, 1992).

No statistically significant laterality effect in the MMNm response was found in the present study in either group, although the MMNm was only significant for nonmusicians in the right hemisphere. Previous behavioral studies have shown evidence of discrete lateralization for contour and interval processing as measured by psychophysical performance in unilateral lesion patients and normal listeners to monaural sound (Liégeois-Chauvel, Peretz, Babaï, Laguitton, \& Chauvel, 1998; Peretz \& Morais, 1987; Peretz, Morais, \& Bertelson, 1987; Zatorre, 1985). It is possible that either the effect is too subtle to detect by our technique, or it occurs at a processing stage after the automatic processes reflected in the MMN. It should also be noted that our stimulation was binaural, as was that of Trainor et al. (2002), who also did not show clear laterality effects. Laterality effects might be seen more clearly with monaural stimulation, and future studies should address this question.

The clear MMNm differences between musicians and nonmusicians observed in our study contribute to the growing literature suggesting that musical training affects a whole network of brain areas, from those involved in stimulus encoding and deviance detection to those involved in conscious evaluation of the music. For example, during passive listening, in addition to the $\mathrm{MMN}$, another preattentive negative response, early right anterior negativity (ERAN, peaking at about 200$250 \mathrm{msec}$ to the violation of musical-harmony syntax), has been demonstrated (Koelsch et al., 2001; Maess, Koelsch, Gunter, \& Friederici, 2001), which is also more pronounced in musicians than in nonmusicians (Koelsch, Schmidt, \& Kansok, 2002). During active discrimination tasks, tonality violation elicits larger late event-related responses in musicians than in nonmusicians, such as the P3 (Trainor et al., 1999; Janata, 1995; Cohen, Granot, Pratt, \& Barneah, 1993) and a long-latency positive component (LPC) around $600 \mathrm{msec}$ (Regnault, Bigand, \& Besson, 2001; Patel, Gibson, Ratner, Besson, \& Holcomb, 1998; Besson \& Faïta, 1995; Besson et al., 1994; Levett \& Martin, 1992; Besson \& Macar, 1987). All these indicate that there must exist multiple parallel processing modules related to various aspects of musical structures. Our results indicate that during the early automatic stages of processing, musical training particularly affects the detection of changes at the abstract level of pitch contour and interval patterns, but has less effect on the detection of simple pitch changes.

\section{METHODS}

\section{Subjects}

Twelve musicians ( 8 women) between 19 and 33 years of age and 12 nonmusically trained adults ( 9 women) between 19 to 40 years of age participated in this study. The musicians had studied more than one instrument and practiced regularly for more than 10 years (10 to 23 , mean 14.3 years) with formal education including musical schools or private lessons. The nonmusicians had almost no formal musical training ( 3 out of 12 had 2 years of lessons and quit playing more than 10 years ago; the rest had none), except in their regular school lessons. None of the subjects in either group had absolute pitch perception. All participants were right-handed as assessed by the Edinburgh handedness test and had normal hearing within the range of 250 to $8000 \mathrm{~Hz}$ as tested by clinical audiometry. The subjects consented to participate after they were completely informed about the nature of the study. The Ethics Commission of the Baycrest Centre for Geriatric Care approved all experimental procedures, which are in accordance with the Declaration of Helsinki.

\section{Stimuli}

The stimuli for both the contour and the interval melodic conditions were composed of sequences of fivenote standard and deviant melodies, with standard melodies occurring $80 \%$ of the time. A sound file was created from digitally recorded piano timbres for each note in audio CD quality. The duration of each note was 300 msec for a total melody length of 1500 msec. The stimulus for the control condition was a sequence of standard and deviant pure tones with different frequencies.

Each melody in the contour condition was uniquely composed of different intervals from the $\mathrm{C}$ major diatonic scale, and each started on one of five different notes from C5 to G5 (American notation) (Figure 4). Thus, the eight melodies were not transpositions of each other. In the corresponding deviant melodies, the first four notes were identical to those of each standard melody. However, the last note was changed to a descending note. Thus, the contour and interval information was identical in the standard and deviant melodies except for the last note, which differed only in contour.

In the interval condition, the standard stimuli consisted of one five-note melody that was transposed to eight keys with starting notes in the same range as those of the contour stimuli. The deviant melodies were derived from the set of standard melodies by raising 
Figure 4. Musical stimuli for the contour (left column) and interval (right column) tasks. In each case, the first four notes of the melodies form a common sequence, which is followed by the standard and deviant terminal note. In the contour case, the interval size changes among melodies, but the standard terminal notes always rise, whereas the deviant terminal notes always fall. In the interval case, the deviant terminal note is higher by a whole tone than standard terminal notes, but the contour of the melody does not change.

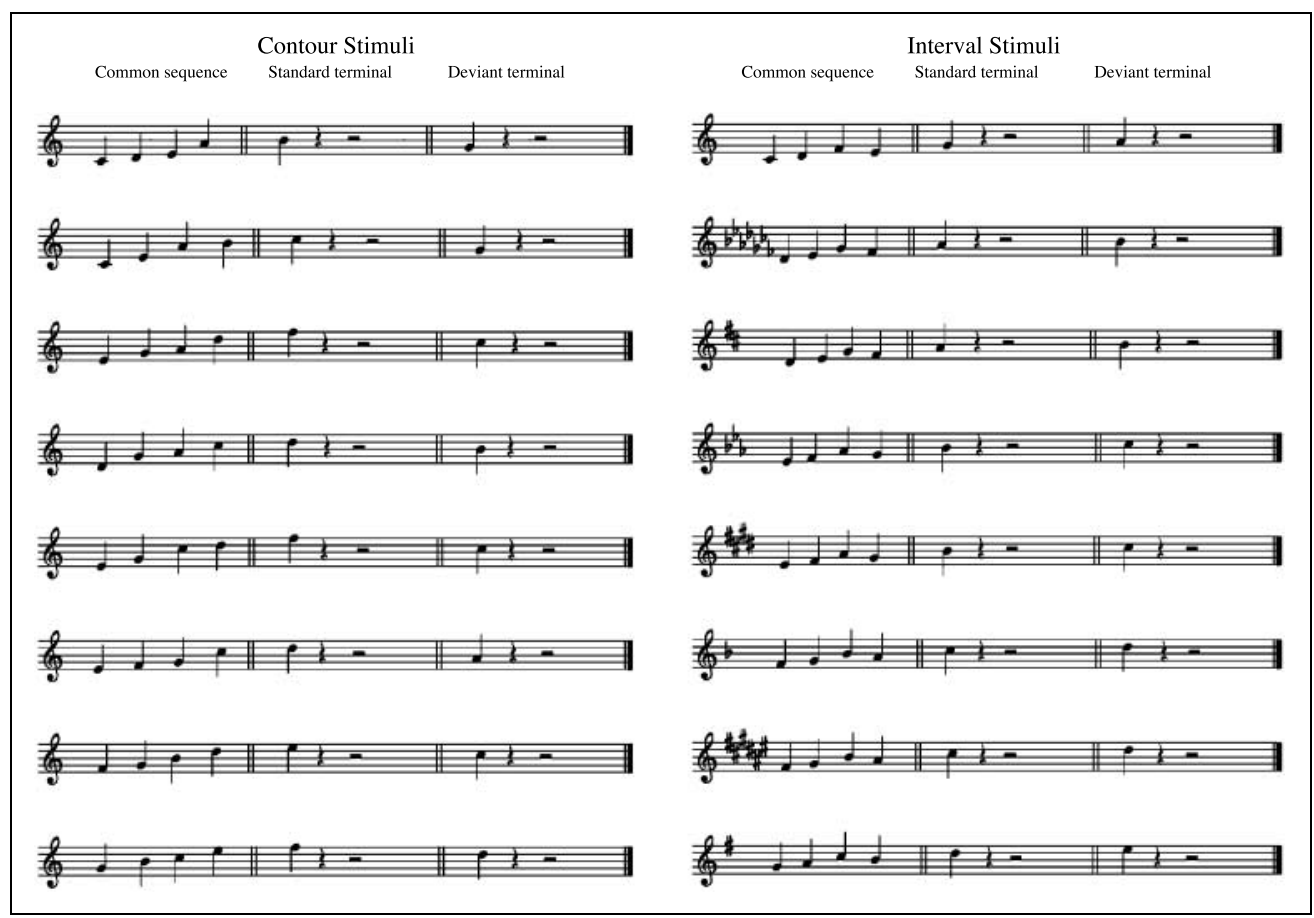

the final note by a whole tone ( $1 / 6$ th of an octave), a change that remained within the key of the melody (Figure 4) and did not change the contour. The first notes of all contour and interval melodies were between C5 and G5, and the last notes were between G5 and F6. The interval size deviations in the contour melodies ranged from a minor second to a major third (1/12 to 4 of an octave) and its mean value was a major second around the median position of termination (B5), which was the same value of deviation exploited in the interval conditions.

Each melody was separated by a 900-msec silent interval. The experimental session consisted of 900 trials of the contour and 900 trials of the interval condition, which were divided into successive blocks of 300 trials taking $12 \mathrm{~min}$ each. The successive deviant trials were separated with at least two standards. In the contour condition, the order of melody variations was pseudorandom. To avoid the appearance of the same note within two successive trials of the interval condition, which might be recognized as "odd" or "primed" despite the interval deviation, the transposition from trial to trial was set to be an upward major third and a downward minor third, until the starting note became G5. Thus, the repeating tonality change resulted in the series "C-E-C\#-F-D-F\#-D\#-G".

The control condition consisted of two successive blocks of 500 pure tones of $300 \mathrm{msec}$ duration, presented with an ISI of $450 \mathrm{msec}$. The frequency of the $80 \%$ standard tones was $990.7 \mathrm{~Hz}$ (B5) and of the $20 \%$ deviant tones $1111.0 \mathrm{~Hz}$ (C\#6). The size of the change was a whole tone, which equals the mean size of that used in the contour and interval conditions. The temporal envelopes of the tones were derived from those of the $\mathrm{B} 5$ and $\mathrm{C} \# 6$ piano tones, respectively.

Hearing thresholds for each subject were determined for the left and right ears for two sounds: the B5 piano sound and the pure tone of $990.7 \mathrm{~Hz}$. In all conditions the stimuli were presented at $60 \mathrm{~dB}$ above those thresholds (the piano thresholds were used for the contour and interval tasks, and the pure tone threshold for the control condition).

\section{MEG Recordings}

The magnetic field responses were recorded with a 151channel whole-cortex magnetometer system (OMEGA, CTF Systems Inc, Port Coquitlam, Canada). The average intersensor spacing of this device is approximately $3.1 \mathrm{~cm}$. The MEG pickup coils of $2 \mathrm{~cm}$ in diameter are configured as first-order axial gradiometers with a $5-\mathrm{cm}$ baseline. The MEG signals were band-pass filtered between 0.1 and $100 \mathrm{~Hz}$ and sampled at a rate of $312.5 \mathrm{sec}^{-1}$. In the melodic conditions, the duration of a recording epoch was $2.2 \mathrm{sec}$ including a $0.4-\mathrm{sec}$ prestimulus period. In the control condition, one epoch was $0.5 \mathrm{sec}$ in duration including a 0.1 -sec prestimulus interval. The onset of the first note of each stimulus synchronized the stimulus presentation and the data acquisition as well. For both melodic conditions three successive recordings, consisting of 300 trials each, were performed, resulting in 72 min total recording time. Two successive recordings of 500 trials each were performed within $15 \mathrm{~min}$ in the control condition. 
The recordings were performed in a sitting position within the magnetically shielded room. The subjects were instructed not to pay attention to the sound stimuli and to watch soundless movies of their own choice, which were projected onto a screen placed in front of the chair. The subject's compliance was verified by video monitoring. The recording session began with the control condition for all subjects. For half of the participants the contour condition was presented first, while for the other half the interval condition was presented first. No explanation about the stimuli was provided.

\section{Data Analysis}

The recorded magnetic field data were averaged selectively for the standard and deviant stimuli and all stimulus types. In order to detect the eye-artifact contaminated epochs, the magnetic field amplitude in a channel located just over the eyes was examined. If it exceeded $1.0 \mathrm{pT}$ in the latency interval between -0.2 to $1.5 \mathrm{sec}$, the data were excluded from the averaging.

The analysis technique of signal space projection (SSP) (Tesche et al., 1995) was applied to the MEG data, which combined the multichannel magnetic field data into a single time series of magnetic dipole moment. The weighting factor of each MEG sensor contributing to the result was the sensitivity of each sensor to a source at the specified location in the brain. This forms a virtual sensor, which is maximally sensitive to a source at the specified origin and orientation and less sensitive to other sources. This results in considerable discrimination against the sensor noise and uncorrelated brain activity from distant brain regions. The SSP is a useful method under the assumption of a single time-varying source at a fixed location. A necessary prerequisite for the SSP is the determination of the source origin and orientation. Therefore, a source analysis using a single equivalent current dipole (ECD) model for the N1m component (latency around $100 \mathrm{msec}$ after the stimulus onset) of the AEF to the first note of the melody regardless of standard or deviant condition was done in both hemispheres for each recorded dataset. For each subject, the average of these dipole locations and orientations across all stimulus conditions served as an estimate for the source in the auditory cortex. Based on these source coordinates the dipole moment waveforms over the whole stimulus-related epochs were calculated for all stimulus conditions. This method allows the averaging of dipole moment waveforms from repeated measurements in the same subject or between subjects. Grand average dipole moment waveforms across both groups of subjects were obtained selectively for the standard and deviant stimuli. Individual difference waveforms were calculated by subtracting the response to the standard from that to the deviant stimuli. MMNm responses were examined after the onset of the fifth note in the melodic conditions and after the onset of the pure tone stimulus in the control condition. The baselines of all responses were adjusted to the mean in a 100-msec interval previous to the onset of the deviation. The 95\% confidence intervals for the grand-averaged response waveforms and the difference waveforms were estimated from nonparametric bootstrap resampling analysis (Davison \& Hinkley, 1997). This method empirically establishes the distribution of the mean from repeated samples of the data itself and allows estimating confidence limits without the assumption of the underlying distribution. This analysis was applied to all data points of the difference waveforms and allowed identifying those time intervals with amplitudes significantly different from zero. Although this method allowed us to measure peak amplitudes and latencies, signal-to-noise ratio was not sufficient to compare source locations across the different conditions.

In order to identify the amplitude of MMNm in the individual data, the peak latencies of grand-averaged difference waveforms were identified in all 12 cases with different parameters (two groups: musicians and nonmusicians; three conditions: control, contour, and interval; two hemispheres). The latency interval was defined as mean of those peak latencies. The single subject's MMNm amplitude was defined as the mean value of the waveforms within the 40-msec time interval centered at the mean peak latency. This procedure was necessary because the identification of peak latency and amplitude in the individual data was not always feasible. The amplitudes of MMNm were statistically examined by a repeated measures ANOVA with one between-subjects factor (group) and two within-subjects factors (condition and hemisphere). The post hoc comparison was calculated with Fisher's PLSD tests using the level of significance as 5\%.

\section{Behavioral Test}

After the MEG recordings, all subjects participated in a behavioral test consisting of two contour and interval discrimination tasks. The tests were designed as two alternative forced-choice tasks (2AFC) with two melodies presented sequentially on each trial. The subjects were instructed to judge whether both melodies were the same or different in terms of one of contour or interval structure. One melody of each trial was chosen from the set of standard stimuli, whereas the other melody was either another standard melody (same) or a deviant melody (different). The melodies were presented in the same order as in the MEG recordings (randomized for the contour task, the same order in the interval task). The same and different pairs occurred with equal probability. The presentation of stimuli and the recording of the subject's responses were controlled by specially developed software on a desktop computer. The stimuli were presented at an intensity of about 60 dBSL through headphones and the subjects re- 
sponded by a mouse click on buttons shown on the computer monitor. The silent interval between the first and the second melody was 900 msec. The next trial started after the subject's response. The subjects were instructed in detail about the tasks and briefly trained by a few trials with feedback until they understood the task correctly. In the actual testing condition no feedback was provided.

All behavioral data were examined statistically by repeated measures ANOVA with one between-subjects factor (group: musicians vs. nonmusicians) and one within-subjects factor (task: contour vs. interval). The post hoc comparison was done with paired $t$ tests for both tasks.

\section{Acknowledgments}

We thank Dr. Claude Alain for helpful comments on a previous version of the manuscript, Ms. Judy Vendramini and Ms. Haydeh Shaghaghi for technical assistance, and the students from the Faculty of Music, University of Toronto, for their participation. This research has been supported by the International Foundation for Music Research, CA, USA.

Reprint requests should be sent to Dr. Christo Pantev, Institute for Biomagnetism and Biosignalanalysis, Münster University Hospital, University of Münster, Kardinal-von-GalenRing 10, 48129 Münster, Germany, or via e-mail: pantev@ uni-muenster.de.

\section{REFERENCES}

Alain, C., Achim, A., \& Woods, D. L. (1999). Separate memory-related processing for auditory frequency and patterns. Psychophysiology, 36, 737-744.

Alain, C., Cortese, F., \& Picton, T. W. (1999). Event-related brain activity associated with auditory pattern processing. NeuroReport, 10, 2429-2434.

Alain, C., Woods, D. L., \& Knight, R. T. (1998). A distributed cortical network for auditory sensory memory in humans. Brain Research, 812, 23-37.

Alain, C., Woods, D. L., \& Ogawa, K. H. (1994). Brain indices of automatic pattern processing. NeuroReport, 6, 140-144.

Alho, K. (1995). Cerebral generators of mismatch negativity $(\mathrm{MMN})$ and its magnetic counterpart (MMNm) elicited by sound changes. Ear and Hearing, 16, 38-51.

Alho, K., Woods, D. L., Algazi, A., Knight, R. T., \& Näätänen, R. (1994). Lesions of frontal cortex diminish the auditory mismatch negativity. Electroencephalography and Clinical Neurophysiology, 91, 353-362.

Allen, J., Kraus, N., \& Bradlow, A. (2000). Neural representation of consciously imperceptible speech sound differences. Perception and Psychophysics, 62, 1383-1393.

Bartlett, J. C., \& Dowling, W. J. (1980). Recognition of transposed melodies: A key-distance effect in developmental perspective. Journal of Experimental Psychology: Human Perception and Performance, 6, 501-515.

Besson, M., \& Faita, F. (1995). An event-related potential (ERP) study of musical expectancy: Comparisons of musicians with non-musicians. Journal of Experimental Psychology: Human Perception and Performance, 21, 1278-1296.
Besson, M., Faïta, F., \& Requin, J. (1994). Brain waves associated with musical incongruities differ for musicians and non-musicians. Neuroscience Letters, 168, 101-105.

Besson, M., \& Macar, F. (1987). An event-related potential analysis of incongruity in music and other non-linguistic contexts. Psychophysiology, 24, 14-25.

Bever, T. G., \& Chiarello, R. J. (1974). Cerebral dominance in musicians and nonmusicians. Science, 185, 537-539.

Brattico, E., Näätänen, R., \& Tervaniemi, M. (2000). Context effects on pitch perception in musicians and nonmusicians: Evidence from event-related-potential recordings. Music Perception, 19, 199-222.

Cheour, M., Ceponiene, R., Lehtokoski, A., Luuk, A., Allik, J., Alho, K., \& Näätänen, R. (1998). Development of language-specific phoneme representations in the infant brain. Nature Neuroscience, 1, 351-353.

Cohen, D., Granot, R., Pratt, H., \& Barneah, A. (1993). Cognitive meanings of musical elements as disclosed by event-related potential (ERP) and verbal experiments. Music Perception, 11, 153-184.

Cuddy, L. L., \& Cohen, A. J. (1976). Recognition of transposed melodic sequences. Quarterly Journal of Experimental Psychology, 28, 255-270.

Dalebout, S. D., \& Stack, J. W. (1991). Mismatch negativity to acoustic differences not differentiated behaviorally. Journal of the American Academy of Audiology, 10, 388-399.

Davison, A. C., \& Hinkley, D. V. (1997). Bootstrap methods and their application. Cambridge: Cambridge University Press.

Deutsch, D. (1999). The psychology of music (2nd ed.). San Diego: Academic Press.

Dowling, W. J. (1978). Scale and contour: Two components of a theory of memory for melodies. Psychological Review, 85, 341-354.

Dowling, W. J. (1982). Contour in context: Comments on Edworthy. Psychomusicology, 2, 47.

Elbert, T., Pantev, C., Wienbruch, C., Rockstroh, B., \& Taub, E. (1995). Increased cortical representation of the fingers of the left hand in string players. Science, 270, 305-307.

Giard, M. H., Perrin, F., Pernier, J., \& Bouchet, P. (1990). Brain generators implicated in the processing of auditory stimulus deviance: A topographic event-related potential study. Psychophysiology, 27, 627-640.

Halpern, A. R., \& Zatorre, R. J. (1999). When that tune runs through your head: A PET investigation of auditory imagery for familiar melodies. Cerebral Cortex, 9, 697-704.

Janata, P. (1995). ERP measures assay the degree of expectancy violation of harmonic contexts in music. Journal of Cognitive Neuroscience, 7, 153-164.

Janata, P., Birk, J. L., Van Horn, J. D., Leman, M., Tillmann, B., \& Bharucha, J. J. (2002). The cortical topography of tonal structures underlying Western music. Science, 298, 2167-2170.

Jäncke, L., Schlaug, G., \& Steinmetz, H. (1997). Hand skill asymmetry in professional musicians. Brain and Cognition, 34, 424-432.

Jäncke, L., Shah, N. J., \& Peters, M. (2000). Cortical activations in primary and secondary motor areas for complex bimanual movements in professional pianists. Brain Research Cognitive Brain Research, 10, 177-183.

Koelsch, S., Gunter, T. C., Schröger, E., Tervaniemi, M., Sammler, D., \& Friederici, A. D. (2001). Differentiating ERAN and MMN: An ERP study. NeuroReport, 12, 1385-1389.

Koelsch, S., Gunter, T. C., Von Cramon, D., Zysset, S., Lohmann, G., \& Friederici, A. D. (2002). Bach speaks: A cortical "language-network" serves the processing of music. Neuroimage, 17, 956-966.

Koelsch, S., Schmidt, B. H., \& Kansok, J. (2002). Effects of musical expertise on the early right anterior negativity: An 
event-related brain potential study. Psychophysiology, 39, 657-663.

Koelsch, S., Schröger, E., \& Tervaniemi, M. (1999). Superior pre-attentive auditory processing in musicians. NeuroReport, 10, 1309-1313.

Kraus, N., McGee, T., Carrell, T. D., \& Sharma, A. (1995). Neurophysiologic bases of speech discrimination. Ear and Hearing, 16, 19-37.

Levänen, S., Ahonen, A., Hari, R., McEvoy, L., \& Sams, M. (1996). Deviant auditory stimuli activate human left and right auditory cortex differently. Cerebral Cortex, 6 , 288-296.

Levett, C., \& Martin, F. (1992). The relationship between complex music stimuli and the late components of the event-related potential. Psychomusicology, 11, 125-140.

Liégeois-Chauvel, C., Peretz, I., Babaï, M., Laguitton, V., \& Chauvel, P. (1998). Contribution of different cortical areas in the temporal lobes to music processing. Brain, 121, 1853-1867.

Maess, B., Koelsch, S., Gunter, T. C., \& Friederici, A. D. (2001) Musical syntax is processed in Broca's area: An MEG study. Nature Neuroscience, 4, 540-545.

Menning, H., Imaizumi, S., Zwitserlood, P., \& Pantev, C. (2002). Plasticity of the human auditory cortex induced by discrimination learning of non-native, mora-timed contrasts of the Japanese language. Learning and Memory, 9, 253-267.

Menning, H., Roberts, L. E., \& Pantev, C. (2000). Plastic changes in the auditory cortex induced by intensive frequency discrimination training. NeuroReport, 11, $817-822$.

Näätänen, R. (1992). Attention and brain function. Hillsdale, NJ: Erlbaum.

Näätänen, R., \& Alho, K. (1997). Mismatch negativity-The measure for central sound representation accuracy. Audiology Neurootology, 2, 341-353.

Näätänen, R., Jiang, D., Lavikainen, J., Reinikainen, K., \& Paavilainen, P. (1993). Event-related potentials reveal a memory trace for temporal features. NeuroReport, 5, 310-312.

Näätänen, R., Lehtokoski, A., Lennes, M., Cheour, M., Huotilainen, M., Iivonen, A., Vainio, M., Alku, P., Ilmoniemi, R. J., Luuk, A., Allik, J., Sinkkonen, J., \& Alho, K. (1997). Language-specific phoneme representations revealed by electric and magnetic brain responses. Nature, 385, 432-434.

Näätänen, R., \& Picton, T. (1987). The N1 wave of the human electric and magnetic response to sound: A review and an analysis of the component structure. Psychophysiology, 24, 375-425.

Ohnishi, T., Matsuda, H., Asada, T., Aruga, M., Hirakata, M., Nishikawa, M., Katoh, A., \& Imabayashi, E. (2001). Functional anatomy of musical perception in musicians. Cerebral Cortex, 11, 754-760.

Opitz, B., Rinne, T., Mecklinger, A., Von Cramon, D., \& Schröger, E. (2002). Differential contribution of frontal and temporal cortices to auditory change detection: fMRI and ERP results. Neuroimage, 15, 167-174.

Paavilainen, P., Jaramillo, M., \& Näätänen, R. (1998). Binaural information can converge in abstract memory traces. Psychophysiology, 35, 483-487.

Pantev, C., Oostenveld, R., Engelien, A., Ross, B., Roberts, L. E., \& Hoke, M. (1998). Increased auditory cortical representation in musicians. Nature, 392, 811-814.

Pantev, C., Roberts, L. E., Schulz, M., Engelien, A., \& Ross, B. (2001). Timbre-specific enhancement of auditory cortical representations in musicians. NeuroReport, 12, 169-174.

Patel, A. D., Gibson, E., Ratner, J., Besson, M., \& Holcomb, P. J.
(1998). Processing syntactic relations in language and music: An event-related potential study. Journal of Cognitive Neuroscience, 10, 717-733.

Patel, A. D., Peretz, I., Tramo, M., \& Labreque, R. (1998). Processing prosodic and musical patterns: A neuropsychological investigation. Brain and Language, 61, 123-144.

Peretz, I., \& Babaï, M. (1992). The role of contour and intervals in the recognition of melody parts: Evidence from cerebral asymmetries in musicians. Neuropsychologia, 30, 277-292.

Peretz, I., \& Morais, J. (1987). Analytic processing in the classification of melodies as same or different. Neuropsychologia, 25, 645-652.

Peretz, I., Morais, J., \& Bertelson, P. (1987). Shifting ear differences in melody recognition through strategy inducement. Brain and Cognition, 6, 202-215.

Phillips, C., Pellathy, T., Marantz, A., Yellin, E., Wexler, K., Poeppel, D., McGinnis, M., \& Roberts, T. (2000). Auditory cortex accesses phonological categories: An MEG mismatch study. Journal of Cognitive Neuroscience, 12, 1038-1055.

Picton, T. W., Alain, C., Otten, L., Ritter, W., \& Achim, A. (2000). Mismatch negativity: Different water in the same river. Audiology Neurootology, 5, 111-139.

Platel, H., Price, C., Baron, J. C., Wise, R., Lambert, J., Frackowiak, R. S., Lechevalier, B., \& Eustache, F. (1997). The structural components of music perception. A functional anatomical study. Brain, 120, 229-243.

Regnault, P., Bigand, E., \& Besson, M. (2001). Different brain mechanisms mediate sensitivity to sensory consonance and harmonic context: Evidence from auditory event-related brain potentials. Journal of Cognitive Neuroscience, 13, 241-255.

Ridding, M. C., Brouwer, B., \& Nordstrom, M. A. (2000). Reduced interhemispheric inhibition in musicians. Experimental Brain Research, 133, 249-253.

Rinne, T., Alho, K., Ilmoniemi, M. K., Virtanen, J., \& Näätänen, R. (2000). Separate time behaviors of the temporal and frontal mismatch negativity sources. Neuroimage, 12, $14-19$.

Saarinen, J., Paavilainen, P., Schröger, E., Tervaniemi, M., \& Näätänen, R. (1992). Representation of abstract attributes of auditory stimuli in the human brain. NeuroReport, 3, 1149-1151.

Satoh, M., Takeda, K., Nagata, K., Hatazawa, J., \& Kuzuhara, S. (2001). Activated brain regions in musicians during an ensemble: A PET study. Brain Research Cognitive Brain Research, 12, 101-108.

Scherg, M., Vajsar, J., \& Picton, T. W. (1989). A source analysis of the late human auditory evoked potentials. Journal of Cognitive Neuroscience, 1, 336-355.

Schlaug, G., Jäncke, L., Huang, Y., Staiger, J. F., \& Steinmetz, H. (1995). Increased corpus callosum size in musicians. Neuropsychologia, 33, 1047-1055.

Schlaug, G., Jäncke, L., Huang, Y., \& Steinmetz, H. (1995). In vivo evidence of structural brain asymmetry in musicians. Science, 267, 699-701.

Schneider, P., Scherg, M., Dosch, H. G., Specht, H. J., Gutschalk, A., \& Rupp, A. (2002). Morphology of Heschl's gyrus reflects enhanced activation in the auditory cortex of musicians. Nature Neuroscience, 5, 688-694.

Shahin, A., Bosnyak, D., Trainor, L. J., \& Roberts, L. E. (2003). Enhancement of neuroplastic P2 and N1c auditory evoked potentials in musicians. Journal of Neuroscience, 23, 5545-5552.

Tervaniemi, M., Ilvonen, T., Karma, K., Alho, K., \& Näätänen, R. (1997). The musical brain: Brain waves reveal the neurophysiological basis of musicality in human subjects. Neuroscience Letters, 226, 1-4. 
Tervaniemi, M., Maury, S., \& Näätänen, R. (1994). Neural representations of abstract stimulus features in the human brain as reflected by the mismatch negativity. NeuroReport, 5, 844-846.

Tervaniemi, M., Rytkonen, M., Schröger, E., Ilmoniemi, R. J., \& Näätänen, R. (2001). Superior formation of cortical memory traces for melodic patterns in musicians. Learning and Memory, 8, 295-300.

Tesche, C. D., Uusitalo, M. A., Ilmoniemi, R. J., Huotilainen, M., Kajola, M., \& Salonen, O. (1995). Signal-space projections of MEG data characterize both distributed and well-localized neuronal sources. Electroencephalography and Clinical Neurophysiology, 95, 189-200.

Tiitinen, H., May, P., Reinikainen, K., \& Näätänen, R. (1994). Attentive novelty detection in humans is governed by pre-attentive sensory memory. Nature, 372, 90-92.

Tillmann, B., Janata, P., \& Bharucha, J. J. (2003). Activation of the inferior frontal cortex in musical priming. Brain Research Cognitive Brain Research, 16, 145-161.

Trainor, L. J., Desjardins, R. N., \& Rockel, C. (1999). A comparison of contour and interval processing in musicians and nonmusicians using event-related potentials. Australian Journal of Psychology, 51, 147-153.
Trainor, L. J., McDonald, K. L., \& Alain, C. (2002). Automatic and controlled processing of melodic contour and interval information measured by electrical brain activity. Journal of Cognitive Neuroscience, 14, 1-13.

Trehub, S. E., Trainor, L. J., \& Unyk, A. M. (1993). Music and speech perception in the first year of life. In H. W. Reese \& L. P. Lipsitt (Eds.), Advances in child development and behavior (Vol. 24, pp. 1-35). New York: Academic Press.

Tremblay, K., Kraus, N., \& McGee, T. (1998). The time course of auditory perceptual learning: Neurophysiological changes during speech-sound training. NeuroReport, 9, 3557-3560.

Wallin, N. L., Merker, B., \& Brown, S. (2000). The origins of music. Cambridge: MIT Press.

Winkler, I., Kujala, T., Tiitinen, H., Sivonen, P., Alku, P., Lehtokoski, A., Czigler, I., Csepe, V., Ilmoniemi, R. J., \& Näätänen, R. (1999). Brain responses reveal the learning of foreign language phonemes. Psychophysiology, 36, 638-642.

Zatorre, R. J. (1985). Discrimination and recognition of tonal melodies after unilateral cerebral excisions. Neuropsychologia, 23, 31-41.

Zatorre, R. J., Evans, A. C., \& Meyer, E. (1994). Neural mechanisms underlying melodic perception and memory for pitch. Journal of Neuroscience, 14, 1908-1919. 